\title{
A common polymorphism of CYP4A11 is associated with blood pressure in a Chinese population
}

\author{
Rong Zhang ${ }^{1}$, Jingyi $\mathrm{Lu}^{1}$, Cheng $\mathrm{Hu}^{1}$, Congrong Wang ${ }^{1}$, Weihui $\mathrm{Yu}^{1}$, Xiaojing $\mathrm{Ma}^{1}$, Yuqian Bao ${ }^{1}$, \\ Kunsan Xiang ${ }^{1}$, Youfei Guan ${ }^{2}$ and Weiping Jia ${ }^{1}$
}

Variants of the human CYP4A11, which belongs to the cytochrome P450, family 4, have been reported to be associated with hypertension in general populations. However, data in the Chinese population are limited. This study sought to assess the effect of CYP4A11 on the prevalence of hypertension and blood pressure in a Chinese population. Three tagging single nucleotide polymorphisms, rs9332982, rs 4660980 and rs3890011, were genotyped in 1734 community-based participants. Individuals with secondary hypertension were excluded. Sex-pooled and sex-specific analysis for genotype-phenotype association were both conducted. We found rs9332982 T allele was nominally associated with higher prevalence of hypertension in women after adjustment for covariates (OR: $1.38,95 \% \mathrm{Cl}: 1.06-1.81, P=0.0183$ ). The significance did not retain after Bonferroni correction. In blood pressure analysis restricted to normotensive individuals, rs 4660980 was associated with both systolic $(\beta=-3.17, P=0.0011)$ and diastolic blood pressure $(\beta=-1.75, P=0.0010)$ in men. A common variant on CYP4A11 was associated with blood pressure in a Chinese population. Future studies are needed to confirm our findings. Hypertension Research (2011) 34, 645-648; doi:10.1038/hr.2011.8; published online 17 February 2011

Keywords: CYP4A11; single nucleotide polymorphism; Chinese

\section{INTRODUCTION}

Essential hypertension is a major risk factor for cerebral, cardiac and renal events. ${ }^{1,2}$ It is a late-onset, multifactorially determined pathological condition. The substantial heritability of blood pressure (BP) variability is supposed to facilitate the identification of responsible genes, which might shed light on the pathogenesis of the disease. To date, several variants have been identified by two genome-wide association studies to be associated with BP and hypertension. ${ }^{3,4}$

Human CYP4A11, which belongs to the cytochrome P450, family 4, catalyzes the formation of 20-hydroxyeicosatetraenoic acid (20-HETE) in the kidney. It is now clear that 20-HETE has both pro- and antihypertensive properties. In the renal and peripheral vasculature, 20-HETE is a potent vasoconstrictor that contributes to the autoregulation of renal-blood flow and renal vascular tone. It promotes calcium influx by depolarizing renal vascular smooth muscle cells secondary to blockade of $\mathrm{K}_{\mathrm{Ca}}$ channels and by increasing the conductance of L-type $\mathrm{Ca}^{2+}$ channels. At the level of the renal tubule, 20-HETE inhibits sodium reabsorption, increases sodium excretion and opposes the development of hypertension. However, 20-HETE elevates vascular tone in the afferent arterioles and augments tubuloglomerular feedback responses, which would lower glomerular filtration rate, promote volume retention and elevate $\mathrm{BP} .{ }^{5}$ Given the role of 20-HETE in the regulation of BP, CYP4A11 had gained much research interest. In 2005, Gainer et $a l^{6}$ reported that a functional variant of CYP4A11, T8590C (rs1126742), was related to an increased prevalence of hypertension in two populations of European decent. And this association was supported by several subsequent studies in independent populations. ${ }^{6-10}$ More recently, $-845 \mathrm{~A} / \mathrm{G}$ (rs9332978), located in the promoter region of CYP4A11, was identified by Sugimoto et al. ${ }^{11}$ to be a risk-conferring polymorphism in a Japanese population, strengthening the role for CYP4A11 as a susceptible gene to hypertension.

However, these studies focused on certain variants that were either non-synonymous or located in the promoter region, whereas leaving most of the CYP4A11 gene region unexamined. Besides, genetic association studies need to be replicated in different populations and whether CYP4A11 variants had a role in modulating BP in Chinese remains unknown. By selecting tagging single nucleotide polymorphisms (SNPs), this study aimed to examine the association of CYP4A11 variants with hypertension and BP in a Chinese population.

\section{METHODS}

Subjects

The subjects were selected from the Shanghai Diabetes Study, ${ }^{12}$ a communitybased epidemiological survey for diabetes. Briefly, the Huayang and Caoyang communities, two middle-income communities in Shanghai, were selected for the survey. The target population included residents over 40 years of age who

${ }^{1}$ Department of Endocrinology and Metabolism, Shanghai Jiao Tong University Affiliated Sixth People's Hospital, Shanghai Diabetes Institute, Shanghai Clinical Center of Diabetes, Shanghai, China and ${ }^{2}$ Department of Physiology and Pathophysiology, Peking University Health Science Center, Beiijing, China

Correspondence: Dr W Jia, Department of Endocrinology and Metabolism, Shanghai Jiao Tong University Affiliated Sixth People's Hospital, 600 Yishan Road, Shanghai 200233 , PR China. 
had been living in Shanghai for more than 10 years. Individuals who suffered from secondary hypertension, cancer, severe disability or severe psychiatric disturbance were excluded. A total of 1734 unrelated individuals from Huayang and Caoyang communities were recruited in this study. Hypertension was defined as systolic BP (SBP) $\geqslant 140 \mathrm{~mm} \mathrm{Hg}$ and/or diastolic blood pressure (DBP) $\geqslant 90 \mathrm{~mm} \mathrm{Hg}$, or the self report of disease affection. To fully exclude the confounding effect of diabetes on hypertension, only those subjects with normal glucose regulation (fasting plasma glucose $<6.1 \mathrm{mmoll}^{-1}$ and 2-h plasma glucose $<7.8 \mathrm{mmoll}^{-1}$ confirmed by a standard 75 -g oral glucose tolerance test) were included into the final study cohort. The study protocol was approved by the institutional review board of Shanghai Jiao Tong University Affiliated Sixth People's Hospital, Shanghai, China. All participants gave informed consent before the study.

\section{Clinical measurements}

General anthropometric parameters including height and weight were measured in all subjects. Body mass index (BMI) was calculated as weight/height ${ }^{2}$. $\mathrm{BP}$ measurements were taken three times using a sphygmomanometer in each participant while seated, after $5 \mathrm{~min}$ of rest. The averaged BP was used for subsequent analysis.

\section{SNP selection and genotyping}

On the Basis of data from HapMap Phase 3 Chinese data, we selected three tagging SNPs (rs9332982, rs4660980 and rs3890011) for genotyping using the Tagger software incorporated in Haploview (version 4.1) (see ref, 13). These three SNPs could capture all the SNPs with minor allele frequencies over 0.05 in the region from $6 \mathrm{~kb}$ upstream to $1 \mathrm{~kb}$ downstream of CYP4A11 gene under the threshold of $r^{2}=1$. In addition, T8590C ( $r$ 1126742) was also genotyped, as this SNP had been reported to be associated with hypertension in different populations.

Genomic DNA was extracted from WBCs using a standard phenol-chloroform method. Genotyping was performed by primer extension of multiplex products with detection by matrix-assisted laser desorption/ionization time-offlight mass spectroscopy using a MassARRAY platform (MassARRAY Compact Analyzer; Sequenom, San Diego, CA, USA). The call rates for rs9332982, rs4660980 and rs3890011 were 98.2, 95.4 and $97.2 \%$, respectively. The SNP rs1126742 was excluded from subsequent analysis because of genotyping failure. The average concordance rate based on 100 duplicate pairs for the three SNPs was $99 \%$.

\section{STATISTICAL ANALYSIS}

Allele frequencies for each SNP were calculated by gene counting. The genotype frequency distribution for each variant was tested for HardyWeinberg equilibrium with a chi-square test in case and control groups separately. All the tests were conducted assuming an additive genetic model. The association between genotype and hypertension for each SNP was assessed using the Cochran-Armitage test for trend. The unconditional logistic regression analysis with adjustment for age, BMI and sex (when appropriate) was carried out to evaluate the effect of each variant on the prevalence of hypertension and odds ratios (ORs) with 95\% confidence intervals (CIs) were presented. The multiple linear regression analysis was performed to examine the association between each SNP and BP. Age, BMI and sex (when appropriate) were included in the regression model as covariates. Pairwise linkage disequilibrium (LD) measures were calculated for all DNA samples using Haploview. Haplotype frequencies were estimated using an expectation maximization-based algorithm. ${ }^{14}$ Haplotypes with a frequency of $<0.01$ were excluded. We used the Bonferroni method to adjust for multiple comparisons. As 9, 18 and 12 tests were performed in hypertension prevalence, BP and haplotype analysis, respectively, only those $P$ values of $<0.0055$ (0.05/9), 0.0027 (0.05/18) and $0.0041(0.05 / 12)$ were considered statistically significant. All statistical analyses were performed using SAS for Windows (version 8.0; SAS Institute Cary, NC, USA).
Table 1 Baseline characteristics of hypertensive and normotensive individuals

\begin{tabular}{lccc}
\hline Parameters & Hypertensive & Normotensive & $\mathrm{P}$ \\
\hline $\mathrm{n}$ & 549 & 1185 & \\
Gender, male/female & $266 / 283$ & $448 / 737$ & $<0.0001$ \\
Age, years & $61.34 \pm 12.04$ & $55.54 \pm 12.04$ & $<0.0001$ \\
BMI & $24.83 \pm 3.04$ & $22.94 \pm 2.81$ & $<0.0001$ \\
Systolic pressure, $\mathrm{mm} \mathrm{Hg}$ & $146.12 \pm 15.47$ & $116.24 \pm 11.68$ & $<0.0001$ \\
Diastolic pressure, $\mathrm{mm} \mathrm{Hg}$ & $90.44 \pm 8.68$ & $74.15 \pm 6.37$ & $<0.0001$ \\
\hline
\end{tabular}

For continuous variables, mean $\pm S D$ is shown and for binary variables, the number of individuals is given.

For SNPs with minor allele frequency $(\mathrm{MAF})>0.2$ under an additive genetic model, our entire study cohort had over $80 \%$ power to detect a minimal OR of 1.29 for hypertension, and the control subgroup had over $80 \%$ power to detect a genetic effect of 1.6 and $0.9 \mathrm{~mm} \mathrm{Hg}$ on SBP and DBP, respectively.

\section{RESULTS}

The baseline characteristics of the study population are described in Table 1. Of the entire 1734 subjects, 549 were hypertensive. The prevalence of hypertension for men and women was 37.25 and $27.75 \%$, respectively. Individuals with hypertension were 5.8 years older and had a significantly higher BMI when compared with normotensive individuals. The MAFs for rs9332982, rs4660980 and rs3890011 were 18.2, 19.4 and 47.2\%, respectively. All three SNPs conformed to Hardy-Weinberg equilibrium.

Table 2 shows the results of the association assessment between each polymorphism and hypertension. In total participants and in men, we failed to detect any association between the three SNPs and the prevalence of hypertension. In women, rs9332982 risk T allele was nominally associated with a higher prevalence of hypertension with adjustment for age and BMI (OR: 1.38, 95\%CI: 1.06-1.81, $P=0.0183$ ). However, the $P$-value was not significant $(>0.0055)$ after Bonferroni's correction.

Because the detailed information of the usage of anti-hypertensive agents was not available for the hypertensive subjects, we conducted the BP analysis only in the control group (Table 3). No evidence of association for the three SNPs with BP was observed in women. In total participants, rs4660980 showed a trend toward association with SBP $(P=0.0104)$, although not significant. In the men subgroup, however, rs4660980 was significantly associated with both SBP ( $\beta=-3.19, P=0.0011)$ and DBP $(\beta=-1.75, P=0.0010)$, even at the significance level of 0.0027 after Bonferroni's adjustment.

According to $\left|D^{\prime}\right|$ and $r^{2}$, all three SNPs were in one block (Table 4). These SNPs formed four haplotypes with a frequency of $>0.01$ in our population (Table 5). No haplotype was differently distributed between hypertensive and normotensive subjects, either in the total group or in men. In women, the frequency of the T-T-C haplotype constructed by rs9332982, rs3890011 and rs4660980 was higher for the hypertensive group than for the control group (OR: 1.3179, 95\% CI: 1.0296-1.6868, $P=0.0282$ ). However, the significance did not retain after correction for multiple testings.

\section{DISCUSSION}

In this study, we select three tagging SNPs for genotyping in 1734 unrelated Chinese subjects. The SNP rs4660980 was significantly associated with both SBP and DBP in normotensive men, even after Bonferroni's correction. 
Table 2 Genotype and allele distributions in men and women stratified by the presence or absence of hypertension

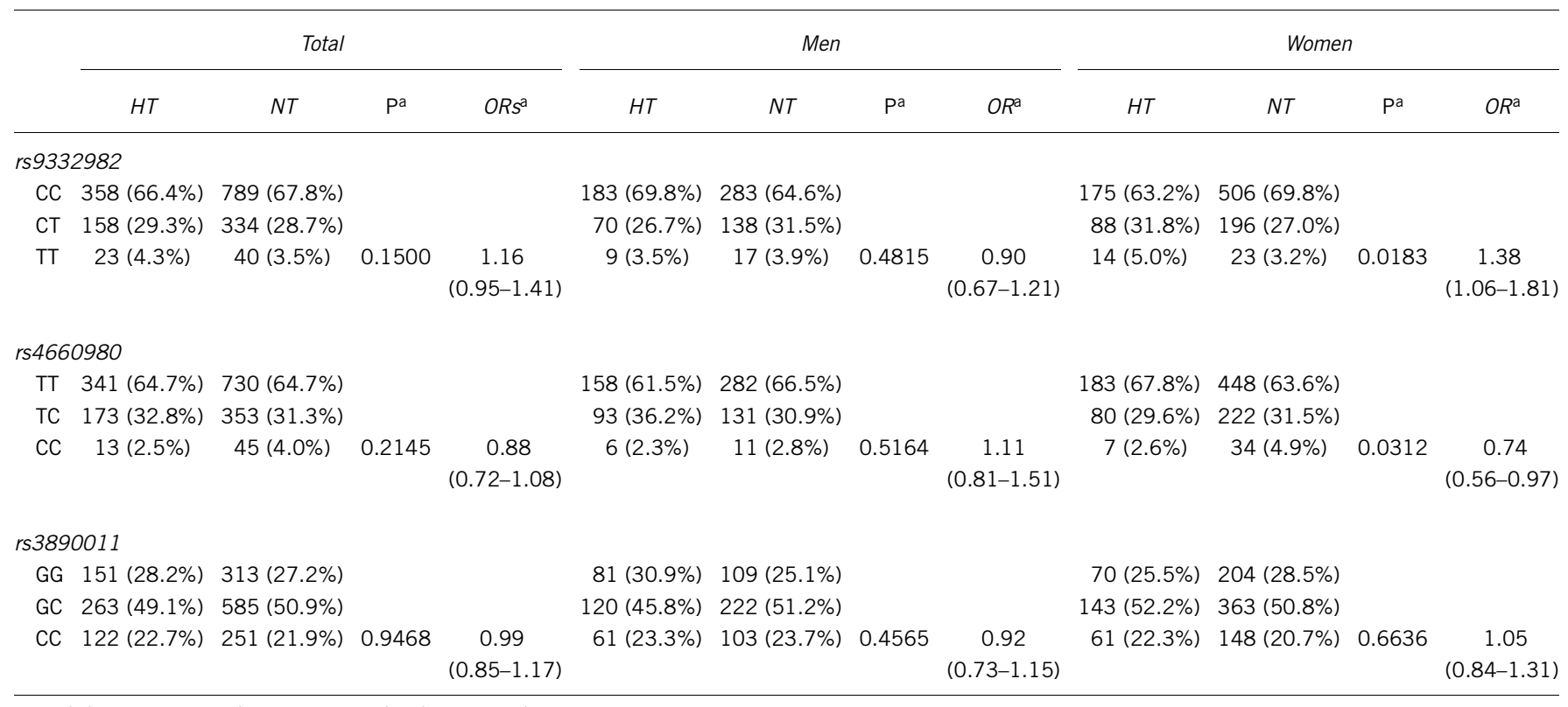

Abbreviations: HT, hypertensive; NT, normotensive; ORs, odds ratios.

a $P$ values are adjusted for age and BMI as covariates.

Table 3 Association of the three SNPs on CYP4A11 with blood pressure in normotensive individuals

\begin{tabular}{|c|c|c|c|c|c|c|c|}
\hline \multirow[b]{2}{*}{ SNPS } & & \multicolumn{3}{|c|}{$S B P$} & \multicolumn{3}{|c|}{$D B P$} \\
\hline & & $\beta$ & $S E$ & $\mathrm{pa}^{\mathrm{a}}$ & $\beta$ & $S E$ & $\mathrm{P}^{\mathrm{a}}$ \\
\hline \multirow[t]{3}{*}{ rs9332982 } & Total & 0.39 & 0.59 & 0.5067 & 0.26 & 0.33 & 0.4367 \\
\hline & Men & 0.46 & 0.91 & 0.6142 & 0.25 & 0.50 & 0.6188 \\
\hline & Women & 0.32 & 0.77 & 0.6756 & 0.25 & 0.44 & 0.5625 \\
\hline \multirow[t]{3}{*}{ rs4660980 } & Total & -1.47 & 0.57 & 0.0104 & -0.49 & 0.33 & 0.1316 \\
\hline & Men & -3.19 & 0.97 & 0.0011 & -1.75 & 0.53 & 0.0010 \\
\hline & Women & -0.68 & 0.71 & 0.3403 & 0.11 & 0.41 & 0.7949 \\
\hline \multirow[t]{3}{*}{ rs3890011 } & Total & -0.77 & 0.46 & 0.0972 & -0.19 & 0.26 & 0.4637 \\
\hline & Men & -1.43 & 0.73 & 0.0516 & -0.73 & 0.40 & 0.0713 \\
\hline & Women & -0.41 & 0.59 & 0.4957 & 0.12 & 0.35 & 0.7248 \\
\hline
\end{tabular}

Abbreviations: DBP, diastolic blood pressure; SBP, systolic blood pressure; SE, standard error; SNPs, single nucleotide polymorphisms.

a $P$ values are adjusted for age, BMI and sex (when appropriate) as covariates.

The metabolism of arachidonic acid by cytochrome P450 (CYP) enzymes leads to the formation of various biologically active eicosanoids, such as hydroxyeicosatetraenoic acids, epoxyeicosatrienoic acids and dihydroxyeicosatrienoic acids. ${ }^{15-17}$ These metabolites have a major role in the regulation of renal vascular tone, tubuloglomerular feedback and sodium transport. Of them, 20-HETE can exert an effect in a pro-hypertensive or anti-hypertensive manner depending on its expression at renovascular or tubular sites. ${ }^{18,19}$

One coding SNP, rs1126742 (T8590C), in exon 11 of CYP4A11 was found to be associated with human $\mathrm{BP}$ and has been replicated in several populations. ${ }^{6-10}$ The $\mathrm{T}$ to $\mathrm{C}$ substitution leads to an $\mathrm{F}$ to $\mathrm{S}$ replacement at amino-acid 434. Compared with F434 (wild type), the S434 replacement reduced by more than half the 20-HETE synthase activity of CYP4A11 (see ref. 6). Although the genotype data of rs1126742 were not available for our study samples, we have sequenced 115 individuals and found this SNP in tight LD with $\mathrm{rs} 4660980\left(D^{\prime}=1, r^{2}=0.95\right)$ (ESM Table 1), which displayed a
Table 4 Pairwise linkage disequilibrium among the three SNPs

\begin{tabular}{lccc}
\hline & \multicolumn{3}{c}{$\left|D^{\prime}\right|$} \\
\cline { 2 - 4 }$r^{2}$ & $r s 9332982$ & $r s 4660980$ & $r s 3890011$ \\
\hline rs9332982 & & 0.97 & 0.99 \\
rs4660980 & 0.05 & & 0.99 \\
rs38900011 & 0.24 & 0.27 & \\
\hline
\end{tabular}

Abbreviation: SNPs, single nucleotide polymorphisms.

$|D|$ above diagonal and $r^{2}$ below diagonal.

significant relation to BP in the current study. rs4660980 maps to intron 9 of CYP4A11 without any known function. In silico analysis with SNP Function Portal (http://brainarray.mbni.med.umich.edu/ Brainarray/Database/SearchSNP/snpfunc.aspx) shows that this SNP, including linked SNPs $\left(D^{\prime} \geqslant 0.8\right)$ registered on Hapmap, does not affect the splicing or transcription of CYP4A11. Thus, we believe that the real association arises from rs1126742 and our finding further supported the role for rs1126742 in the regulation of BP.

It is noteworthy that we used a stringent strategy (Bonferroni) to adjust for multiple comparisons. In spite of the low probability of type I error, some real association may also be underestimated. For instance, we observed in individual SNP test and haplotype analysis that rs9332982T allele was nominally correlated with a higher risk of developing hypertension. Interestingly, rs9332982 was in perfect LD $\left(r^{2}=1\right)$ with rs9332978 according to HapMap HCB data. The latter SNP was recently reported by Sugimoto et al. ${ }^{11}$ rs9332878 locates in the promoter region of CYP4A11. The G allele may decrease transcriptional activation of CYP4A11, thus leading to lower 20-HETE production in the kidney. Taken together, we suggest that studies with large sample size may be needed to clarify the effect of rs9332978 on $\mathrm{BP}$ in different populations.

One major limitation of this study resides in relatively low statistical power to detect a modest effect, especially in subgroup analyses (ESM tables 2, 3 and 4). For example, the power for rs9332982 (MAF 18\%) 
Table 5 Association between the haplotypes of CYP4A11 and hypertension in women

\begin{tabular}{|c|c|c|c|c|c|c|c|}
\hline \multirow[b]{2}{*}{ Haplotypes } & \multicolumn{3}{|c|}{ SNPS } & \multicolumn{2}{|c|}{ Frequency } & \multirow[b]{2}{*}{ OR $(95 \% \mathrm{Cl})$} & \multirow[b]{2}{*}{$P$} \\
\hline & rs9332982 & rs4660980 & $r s 3890011$ & $H T$ & $N T$ & & \\
\hline 2 & C & c & C & 0.177 & 0.207 & $0.8228(0.6391-1.0592)$ & 0.1290 \\
\hline 3 & $\mathrm{~T}$ & $\mathrm{~T}$ & C & 0.209 & 0.167 & 1.3179 (1.0296-1.6868) & 0.0282 \\
\hline 4 & C & $\mathrm{T}$ & $\mathrm{C}$ & 0.094 & 0.083 & $1.1381(0.8093-1.6004)$ & 0.4601 \\
\hline
\end{tabular}

Abbreviations: $\mathrm{Cl}$, confidence intervals; HT, hypertensive; NT, normotensive; ORs, odds ratios; SNPs, single nucleotide polymorphisms.

and rs4660980 (MAF 19\%) to detect an OR of 1.3 in women assuming an additive model was 56 and 58\%, respectively, and the power decreases in the men subgroup. The resulting statistical fluctuation may, at least partially, explain the discrepancy between men and women with respect to nominal association signals. Another limitation is the lack of data of serum or urinary 20-HETE, the measurement of which may give a hint to the functional relevance of susceptible SNPs in the modulation of BP.

In summary, rs4660980 was associated with both SBP and DBP in men. Given the tight LD between rs4660980 and rs1126742 (T8590C), this study provides further evidence for rs1126742 in the regulation of BP. Another SNP, rs9332982, showed a nominal association with hypertension prevalence in women, suggesting that the previous reported rs9332978, in perfect LD with rs9332982, may be worthy of investigation in the future.

\section{CONFLICT OF INTEREST}

The authors declare no conflicts of interest.

\section{ACKNOWLEDGEMENTS}

We thank all the participants of this research. We thank all nursing and medical staffs at Shanghai Clinical Center for Diabetes for their dedication in this study. This work was supported by grants from the Project of National Natural Science Foundation of China (NSFC) (30630061), National 973 Program of China (2006CB503901), National 863 Program of China (2006AA02A409), Major Program of Shanghai Municipality for Basic Research (08dj1400601) and Shanghai Key Laboratory of Diabetes Mellitus (08DZ2230200), China.

1 Bakris GL, Williams M, Dworkin L, Elliott WJ, Epstein M, Toto R, Tuttle K, Douglas J, Hsueh W, Sowers J. Preserving renal function in adults with hypertension and diabetes: a consensus approach. National Kidney Foundation Hypertension and Diabetes Executive Committees Working Group. Am J Kidney Dis 2000; 36: 646-661.

2 Stokes III J, Kannel WB, Wolf PA, D'Agostino RB, Cupples LA. Blood pressure as a risk factor for cardiovascular disease. The Framingham Study-30 years of follow-up. Hypertension 1989; 13: I13-I18.

3 Levy D, Ehret GB, Rice K, Verwoert GC, Launer LJ, Dehghan A, Glazer NL, Morrison AC, Johnson AD, Aspelund T, Aulchenko Y, Lumley T, Kottgen A, Vasan RS, Rivadeneira F, Eiriksdottir G, Guo X, Arking DE, Mitchell GF, Mattace-Raso FU, Smith AV, Taylor K, Scharpf RB, Hwang SJ, Sijbrands EJ, Bis J, Harris TB, Ganesh SK, O'Donnell CJ, Hofman A, Rotter JI, Coresh J, Benjamin EJ, Uitterlinden AG, Heiss G, Fox CS, Witteman JC, Boerwinkle E, Wang TJ, Gudnason V, Larson MG, Chakravarti A, Psaty BM, van Duijn CM. Genome-wide association study of blood pressure and hypertension. Nat Genet 2009; 41: 677-687.

4 Newton-Cheh C, Johnson T, Gateva V, Tobin MD, Bochud M, Coin L, Najjar SS, Zhao JH, Heath SC, Eyheramendy S, Papadakis K, Voight BF, Scott LJ, Zhang F, Farrall M, Tanaka T, Wallace C, Chambers JC, Khaw KT, Nilsson P, van der Harst P, Polidoro S, Grobbee DE, Onland-Moret NC, Bots ML, Wain LV, Elliott KS, Teumer A, Luan J, Lucas G, Kuusisto J, Burton PR, Hadley D, McArdle WL, Brown M, Dominiczak A, Newhouse SJ, Samani NJ, Webster J, Zeggini E, Beckmann JS, Bergmann S, Lim N, Song K, Vollenweider P, Waeber G, Waterworth DM, Yuan X, Groop L, Orho-Melander M, Allione A, Di Gregorio A, Guarrera S, Panico S, Ricceri F, Romanazzi V, Sacerdote C, Vineis P, Barroso I, Sandhu MS, Luben RN, Crawford GJ, Jousilahti P, Perola M, Boehnke M,
Bonnycastle LL, Collins FS, Jackson AU, Mohlke KL, Stringham HM, Valle TT, Willer CJ, Bergman RN, Morken MA, Doring A, Gieger C, Illig T, Meitinger T, Org E, Pfeufer A, Wichmann HE, Kathiresan S, Marrugat J, O'Donnell CJ, Schwartz SM, Siscovick DS, Subirana I, Freimer NB, Hartikainen AL, McCarthy MI, O'Reilly PF, Peltonen L, Pouta A, de Jong PE, Snieder H, van Gilst WH, Clarke R, Goel A, Hamsten A, Peden JF, Seedorf U, Syvanen AC, Tognoni G, Lakatta EG, Sanna S, Scheet P, Schlessinger D, Scuteri A, Dorr M, Ernst F, Felix SB, Homuth G, Lorbeer R, Reffelmann T, Rettig R, Volker U, Galan P, Gut IG, Hercberg S, Lathrop GM, Zelenika D, Deloukas P, Soranzo N, Williams FM, Zhai G, Salomaa V, Laakso M, Elosua R, Forouhi NG, Volzke H, Uiterwaal CS, van der Schouw YT, Numans ME, Matullo G, Navis G, Berglund G, Bingham SA, Kooner JS, Connell JM, Bandinelli S, Ferrucci L, Watkins H, Spector TD, Tuomilehto J, Altshuler D, Strachan DP, Laan M, Meneton P, Wareham NJ, Uda M, Jarvelin MR, Mooser V, Melander O, Loos RJ, Elliott P, Abecasis GR, Caulfield M, Munroe PB. Genome-wide association study identifies eight loci associated with blood pressure. Nat Genet 2009; 41: 666-676.

5 Hoagland KM, Maier KG, Moreno C, Yu M, Roman RJ. Cytochrome P450 metabolites of arachidonic acid: novel regulators of renal function. Nephrol Dial Transplant 2001; 16: 2283-2285.

6 Gainer JV, Bellamine A, Dawson EP, Womble KE, Grant SW, Wang Y, Cupples LA, Guo CY, Demissie S, O'Donnell CJ, Brown NJ, Waterman MR, Capdevila JH. Functional variant of CYP4A11 20-hydroxyeicosatetraenoic acid synthase is associated with essential hypertension. Circulation 2005; 111: 63-69.

7 Fu Z, Nakayama T, Sato N, Izumi Y, Kasamaki Y, Shindo A, Ohta M, Soma M, Aoi N, Sato M, Ozawa Y, Ma Y. A haplotype of the CYP4A11 gene associated with essential hypertension in Japanese men. J Hypertens 2008; 26: 453-461.

8 Gainer JV, Lipkowitz MS, Yu C, Waterman MR, Dawson EP, Capdevila JH, Brown NJ. Association of a CYP4A11 variant and blood pressure in black men. J Am Soc Nephrol 2008; 19: 1606-1612.

9 Mayer B, Lieb W, Gotz A, Konig IR, Aherrahrou Z, Thiemig A, Holmer S, Hengstenberg C, Doering A, Loewel H, Hense HW, Schunkert H, Erdmann J. Association of the T8590C polymorphism of CYP4A11 with hypertension in the MONICA Augsburg echocardiographic substudy. Hypertension 2005; 46: 766-771.

10 Mayer B, Lieb W, Gotz A, Konig IR, Kauschen LF, Linsel-Nitschke P, Pomarino A, Holmer S, Hengstenberg C, Doering A, Loewel H, Hense HW, Ziegler A, Erdmann J, Schunkert $\mathrm{H}$. Association of a functional polymorphism in the CYP4A11 gene with systolic blood pressure in survivors of myocardial infarction. J Hypertens 2006; 24: 1965-1970.

11 Sugimoto K, Akasaka H, Katsuya T, Node K, Fujisawa T, Shimaoka I, Yasuda O, Ohishi M, Ogihara T, Shimamoto K, Rakugi H. A polymorphism regulates CYP4A11 transcriptional activity and is associated with hypertension in a Japanese population. Hypertension 2008; 52: 1142-1148.

12 Jia WP, Pang C, Chen L, Bao YQ, Lu JX, Lu HJ, Tang JL, Wu YM, Zuo YH, Jiang SY, Xiang KS. Epidemiological characteristics of diabetes mellitus and impaired glucose regulation in a Chinese adult population: the Shanghai Diabetes Studies, a crosssectional 3-year follow-up study in Shanghai urban communities. Diabetologia 2007; 50: 286-292.

13 Barrett JC, Fry B, Maller J, Daly MJ. Haploview: analysis and visualization of LD and haplotype maps. Bioinformatics 2005; 21: 263-265.

14 Qin ZS, Niu T, Liu JS. Partition-ligation-expectation-maximization algorithm for haplotype inference with single-nucleotide polymorphisms. Am J Hum Genet 2002; 71: 1242-1247.

15 Campbell WB, Harder DR. Endothelium-derived hyperpolarizing factors and vascular cytochrome P450 metabolites of arachidonic acid in the regulation of tone. Circ Res 1999; 84: 484-488.

16 Capdevila JH, Wei S, Yan J, Karara A, Jacobson HR, Falck JR, Guengerich FP, DuBois RN. Cytochrome P-450 arachidonic acid epoxygenase. Regulatory control of the renal epoxygenase by dietary salt loading. J Biol Chem 1992; 267: 21720-21726.

17 Node K, Huo Y, Ruan X, Yang B, Spiecker M, Ley K, Zeldin DC, Liao JK. Antiinflammatory properties of cytochrome P450 epoxygenase-derived eicosanoids. Science 1999; 285: 1276-1279.

18 McGiff JC, Quilley J. 20-hydroxyeicosatetraenoic acid and epoxyeicosatrienoic acids and blood pressure. Curr Opin Nephrol Hypertens 2001; 10: 231-237.

19 Roman RJ. P-450 metabolites of arachidonic acid in the control of cardiovascular function. Physiol Rev 2002; 82: 131-185.

Supplementary Information accompanies the paper on Hypertension Research website (http://www.nature.com/hr) 